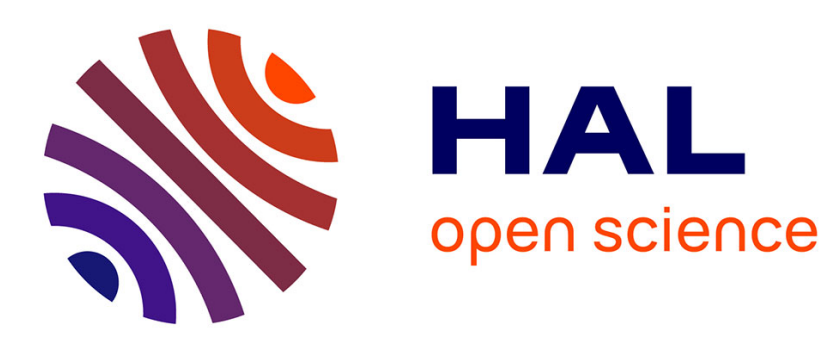

\title{
Electrospun Azido-PCL Nanofibers for Enhanced Surface Functionalization by Click Chemistry
}

\author{
Anica Lancuški, Sebastien Fort, Frederic Bossard
}

\section{To cite this version:}

Anica Lancuški, Sebastien Fort, Frederic Bossard. Electrospun Azido-PCL Nanofibers for Enhanced Surface Functionalization by Click Chemistry. ACS Applied Materials \& Interfaces, 2012, 4 (12), pp.6499-6504. 10.1021/am301458y . hal-01170743

\section{HAL Id: hal-01170743 \\ https://hal.science/hal-01170743}

Submitted on 16 Jan 2019

HAL is a multi-disciplinary open access archive for the deposit and dissemination of scientific research documents, whether they are published or not. The documents may come from teaching and research institutions in France or abroad, or from public or private research centers.
L'archive ouverte pluridisciplinaire HAL, est destinée au dépôt et à la diffusion de documents scientifiques de niveau recherche, publiés ou non, émanant des établissements d'enseignement et de recherche français ou étrangers, des laboratoires publics ou privés. 


\title{
Electrospun Azido-PCL Nanofibers for Enhanced Surface Functionalization by Click Chemistry
}

\author{
Anica Lancuški, ${ }^{\not, \dagger}$ Sébastien Fort, ${ }^{\dagger}$ Frédéric Bossard ${ }^{*}, t$ \\ ¥Laboratoire Rhéologie et Procédés, Université Joseph-Fourier - Grenoble Institut National \\ Polytechnique, 1301 rue de la piscine, 38041 Grenoble Cedex 9, France \\ ${ }^{\dagger}$ Centre de Recherches sur les Macromolécules Végétales, UPR, CNRS, 5301, BP53, 38041 \\ Grenoble Cedex 9, France. Affiliated with University Joseph Fourier Grenoble and member of \\ Institut de Chimie Moléculaire de Grenoble ICMG FR CNRS 2607
}

\begin{abstract}
This paper reports highly surface functionalized and 'clickable' $\alpha, \omega$-azido-poly $(\varepsilon-$ caprolactone) fibers (f-PCL-N 3 ), obtained by classical electrospinning setup. Azidefunctionalized PCL was obtained from a commercially available $\alpha, \omega$-poly( $\varepsilon$-caprolactone)-diol, $\mathrm{PCL}_{2}$, and electrospun with a non-derivative high molecular weight PCL. Successful chemical modifications of $\mathrm{PCL}_{2}$ were confirmed by NMR, FTIR and MALDI-TOF mass spectroscopy. High content of surface azides, as a response to high electric field applied, was characterized using colorimetric assay. In addition, azide reduction to amines revealed a non-destructive route for highly amine-functionalized fibers. Fluorescence labeling of f-PCL-N $\mathrm{N}_{3}$ fibers with FITC-
\end{abstract}


alkyne fluorophore proved that the azide groups are mainly surface-localized as well as highly available for click-chemistry coupling.

KEYWORDS electrospinning, nanofibers, polycaprolactone, azides, click chemistry, surface functionalization

\section{Introduction}

Nanofibers with a high specific surface area are of the outmost importance in the field of biomaterials science and bioengineering. ${ }^{1,2}$ Particularly, polyesters have been often employed as a material of choice for biomedical applications. ${ }^{3}$ In order to prepare biomaterials with enhanced properties, their practice has been frequently followed by additional functionalization and/or surface modifications. ${ }^{4,5}$ Several works on chemical functionalization, notably wet chemical methods ${ }^{6}$ and plasma treatment. ${ }^{7}$ Although these methods are simple and easy to use, they induce changes in surface morphology and degradation of a material. Azide-alkyne cycloaddition is a valuable technique for introducing broad functional moieties owing to its versatility and high yields. It was for the first time reported by Huisgen ${ }^{8,9}$ under high temperatures and in organic solvents. Sharpless et al. ${ }^{10}$ discovered that copper(I)-catalyzed azide-alkyne cycloadditions (CuAAc), popularized as click chemistry, could be performed at ambient temperature and in aqueous phase. Soon, click chemistry concept becomes a simple solution for long known challenges - synthesis of complex polymer structures as co-polymers and dendrimers, ${ }^{11}$ bioconjugation $^{12}$ and surface functionalization. ${ }^{13}$ The combination of electrospinning, a nanofiber-producing process described further, and click chemistry resulted in a number of interesting studies. ${ }^{14-16}$ However, these reports reveal complex preparation of a desired polymer 
from a previously modified monomer ${ }^{17}$ and usually low surface-functionalization rate. Thus, it is of significant importance to investigate a new, simple and non-aggressive path for obtaining highly decorated surface as well as biocompatible nanofibers, able to immobilize various bioactive molecules by means of click chemistry.

Among all the existing processes, electrospinning is a straight forward route for obtaining nanofibrous materials with a high surface-to-volume ratio. ${ }^{18}$ The process consists of drawing continuous fibers of micro- and nano-diameters from electrically charged jet of a polymer solution or a melt. ${ }^{19} \mathrm{~A}$ high electric field causes the polymer drop to distort into a Taylor Cone from which an electrically charged jet is emitted. Accumulated charges will result in bending instability and acceleration of the jet towards the collector where solid fibers will be deposited. ${ }^{20}$

Nanofibers based on poly(e-caprolactone) (PCL) are known as a promising material for biomedical applications because of their biodegradability and biocompatibility. ${ }^{21}$ However, the absence of functional groups has put forward many studies about PCL surface modifications where functionalization of the fiber meshes is followed by polymer degradation and surface erosion. ${ }^{22-24}$ In the present work, blends of two PCL, with a high molecular weight, $\mathrm{PCL}_{80}(\mathrm{Mn}$ $\left.\sim 80000 \mathrm{~g} \mathrm{~mol}^{-1}\right)$ and low molecular weight PCL-N $3\left(\mathrm{Mn} \sim 2300 \mathrm{~g} \mathrm{~mol}^{-1}\right)$ were used in different ratios in the electrospinning process. $\mathrm{PCL}_{80}$ provides optimal electrospinning conditions and good mechanical properties of the fibers while PCL-N $\mathrm{N}_{3}$ is used to functionalize nanofibers. Using standard electrospinning setup, we obtained surface-decorated azido fibers, f- PCL-N $\mathrm{N}_{3}$. We exposed a promising and efficient way of obtaining clickable nano-fibrous scaffolds from commercially available poly(E-caprolactone)s, with functionalized groups localized mainly on the surface and accessible for the CuAAc coupling. The versatility of tuning the fiber's surface 
with a desired bio-molecule (peptides, carbohydrates, etc) gives access of these scaffolds to a potential use in regenerative medicine, drug delivery or tissue engineering.

\section{Experimental Section}

Materials: Poly( $\varepsilon$-caprolactone) ( $\left.\mathrm{PCL}_{80}\right) \mathrm{M}_{\mathrm{n}} 70000-90000 \mathrm{~g} /$ mol, triethylamine TEA, sodium chloride- saturated $(\mathrm{NaCl})$, sodium azide $\left(\mathrm{NaN}_{3}\right)$, sodium sulphate $\left(\mathrm{Na}_{2} \mathrm{SO}_{4}\right)$, hydrochloric acid (HCl), 18-crown-6, p-toluene sulfonylchloride $(\mathrm{TsCl})$, triphenylphosphine $\left(\mathrm{PPh}_{3}\right)$, ninhydrin, hydrindantine, fluorescein isothiocyanate (FITC), propargyl amine, copper (II) sulfate pentahydrate $\left(\mathrm{CuSO}_{4} \times 5 \mathrm{H}_{2} \mathrm{O}\right)$, sodium ascorbate and all organic solvents were purchased from Sigma Aldrich and used without further purification. $\alpha, \omega$-poly( $\varepsilon$-caprolactone)-diol ( $\left.\mathrm{PCL}_{2}\right), \mathrm{M}_{\mathrm{n}}$ $2000 \mathrm{~g} \mathrm{~mol}^{-1}$ (Sigma), was recrystallized from diethyl ether prior to use.

Synthesys of $\alpha, \omega$-azide-poly( $\varepsilon$-caprolactone): Modifications of the $\mathrm{PCL}_{2}$ took place at the chain ends, having as an objective to replace the hydroxyl with azido groups. ${ }^{25} \mathrm{PCL}_{2}(2 \mathrm{~g}, 1$ mmol) was dissolved in $30 \mathrm{ml}$ of dichloromethane in a $100 \mathrm{ml}$ round-bottom-flask and stirred until dissolution. Then, triethylamine (6 eq, $0.607 \mathrm{~g}$ ) and $\mathrm{TsCl}(6 \mathrm{eq}, 1.14 \mathrm{~g})$ dissolved in $20 \mathrm{ml}$ of DCM were added drop-wise into the polymer solution. After $28 \mathrm{~h}$ at room temperature, the reaction mixture was then washed with saturated $\mathrm{NaCl}, \mathrm{HCl} 1 \mathrm{M}$ and $\mathrm{H}_{2} \mathrm{O}$. The organic phase was dried over $\mathrm{Na}_{2} \mathrm{SO}_{4}$ and concentrated. The crude product was dissolved in the minimum of $\mathrm{CH}_{2} \mathrm{Cl}_{2}$ and then precipitated in cold $\left(4^{\circ} \mathrm{C}\right)$ diethyl ether $(10 \mathrm{ml})$ to give $\alpha, \omega$-p-toluenesulfonylpoly(E-caprolactone) (PCL-OTs) intermediate $(1.21 \mathrm{~g}, 54 \%$ yield). PCL-OTs (1 g, 0.4332 mmol) was then dissolved in the minimum of DMF $(5 \mathrm{ml})$. When the polymer was dissolved, $\mathrm{NaN}_{3}$ (6 eq, $0.169 \mathrm{~g}$ ) was added with 1-2 crystals of 18-crown-6 and the reaction was stirred for 
$24 \mathrm{~h}$ at $50{ }^{\circ} \mathrm{C}$ under gas Argon. After precipitation in cold water $(20 \mathrm{ml}), 0.875 \mathrm{~g}$ of the final product $\alpha, \omega$-azido-poly( $\varepsilon$-caprolactone) $\left(\mathrm{PCL}-\mathrm{N}_{3}\right)$ was isolated (98\% yield).

Preparation of electrospun f-PCL-N3 fibers: All polymer solutions for electrospinning were prepared in dichoromethane/methanol (DCM:MeOH 4:1) solvent mixture at room temperature. A high molecular weight PCL 80 and PCL-N 3 were blended in different ratios $(20,40$ and $60 \mathrm{wt} \%$ of PCL-N $\mathrm{N}_{3}$ ) to give a final concentration of 10,16 and $23 \mathrm{wt} \%$ of polymer in $\mathrm{DCM} / \mathrm{MeOH}$ solvent mixture, respectively. Polymer content in electrospinning solution is calculated as a mass of the polymer divided by the total mass of both polymer and solvent mixture using the following equation:

$$
w t \%=\frac{(\text { mass of polymer })}{(\text { mass of polymer }+ \text { mass of solvent })} \times 100 \%
$$

Preparation of polymer film: $\mathrm{PCL}_{80}$ and PCL-N $3\left(60 \mathrm{wt} \%\right.$ of PCL-N $\mathrm{N}_{3}$ in the blend) were dissolved in DCM:MeOH (volume ratio 4:1) solvent mixture to a final concentration of $23 \mathrm{wt} \%$. Polymer cast film was obtained from the solution deposited onto a glass slide that was kept in a vacuum oven at $60{ }^{\circ} \mathrm{C}$ for 20 minutes.

Synthesis of propargyl-fluorescein isothiocyanate: Fluorescein isothiocyanate (FITC) (10 $\mathrm{mg}, 0.0128 \mathrm{mmol})$ and propargyl amine $(90 \mu \mathrm{l}, 0.703 \mathrm{mmol})$ were dissolved in $110 \mu \mathrm{l}$ of DMF in a microcentrifuge tube and stirred in dark for $24 \mathrm{~h}$ at room temperature. ${ }^{26} \mathrm{DMF}$ and excess of propargyl amine were then evaporated and crude product was dissolved in stock solution mixture of acetonitrile/water (1:1).

Surface modification of f-PCL-N 3 fibrous scaffolds: Reaction click between propargyl-FITC and azido-fibers in heterogeneous phase is described on the f-PCL-N $3-60$ fibers as example. Prior use, 0,1 $\mathrm{M}$ solutions of $\mathrm{CuSO}_{4}$ and of sodium ascorbate, as well as FITC solution in acetonitrile/water, were filtered through PTFE $(0,2 \mu \mathrm{m})$ filter in order to eliminate possible 
undissolved crystals that could aggregate on the fibers. f-PCL-N $3-60$ fibers $(2 \mathrm{mg})$ were put in the microcentrifuge tube containing $500 \mu 1$ of acetonitrile, and then $56 \mu 1$ (10 eq per azide group on the surface, as estimated by the ninhydrin assay) solution $(6,42 \mathrm{mmol} / \mathrm{l})$ of FITC-alkyne in acetonitrile/water (1:1) along with $500 \mu \mathrm{l}$ of distilled water, $7 \mu \mathrm{l} \mathrm{CuSO}{ }_{4} \cdot 5 \mathrm{H}_{2} \mathrm{O}$ in distilled water $(0.1 \mathrm{M}, 6$ eq) and $7 \mu 1$ of sodium ascorbate in distilled water $(0.1 \mathrm{M}, 6$ eq) were added. Reaction mixture was stirred in dark for $24 \mathrm{~h}$ at room temperature and then fibers were thoroughly washed with acetonitrile/water (1:1). f-PCL- $\mathrm{N}_{3}-40$ and f-PCL- $\mathrm{N}_{3}-20$ were prepared using same procedure by keeping the same molar ratio. Resulting f-PCL-N $3-20-F I T C$, f-PCL-N $3-40-F I T C$ and f-PCL-N3-60-FITC fibers were kept in acetonitrile/water (1:1) stock solution until observation.

Methods: Electrospinning process was performed with a horizontal setup - a $5 \mathrm{ml}$ syringe was filled with appropriate polymer solution and placed on the syringe pump with the blunt 21-gouge needle attached. Flow rate was controlled by a syringe pump (KD Scientific series 200, USA) in the range from 0.01 to $0.02 \mathrm{ml} / \mathrm{min}$. A rotating cylinder $(113.5 \mathrm{~mm}$ diameter, $250 \mathrm{~mm}$ length and rotating speed of $420 \mathrm{rpm}$ ) was used as a collector. The distance between needle tip and collector was fixed at $15 \mathrm{~cm}$. Applied voltage (dual high voltage power supply, $\pm 30 \mathrm{kV}$, iseq GMBH Germany) ranges from 11 to $15 \mathrm{kV}$. All experiments were done at room temperature. The relative humidity noted was between 30 and $55 \%$.

FTIR spectra were recorded in the transmission mode using a Perkin-Elmer 1720X FTIR instrument.

${ }^{1} \mathrm{H}$ and ${ }^{13} \mathrm{C}$ NMR spectra were obtained with a Bruker AVANCE $400 \mathrm{MHz}$ with 5mm QNP probe at $298 \mathrm{~K}$. 
Matrix Assisted Laser Desorption Ionization - Time of Flight Mass Spectroscopy (MALDITOF MS) analyses were done in the ionization mode with Autoflex Bruker instrument.

Quantification of azide groups: Ninhydrin test was adapted for the detection and quantification of the azide $\left(-\mathrm{N}=\mathrm{N}^{+}=\mathrm{N}^{-}\right)$groups on PCL fibers. f-PCL-N $\mathrm{N}_{3}$ fibers $(10 \mathrm{mg})$ were dropped in $10 \mathrm{~g} / 1$ $\mathrm{PPh}_{3}$ solution in ethanol $(2 \mathrm{ml})$ for 15 minutes in order to reduce the azide to amine groups. Reduced f-PCL-N $\mathrm{N}_{3}$ fibers were washed in ethanol and then dissolved in 1,4-dioxane (500 $\mu$ l). Solution mixture of ninhydrin $(2 \mathrm{~g})$ and hydrindantin $(0.3 \mathrm{~g})$ in $75 \mathrm{ml}$ DMSO and sodium acetate buffer $(25 \mathrm{ml})$ was prepared under argon and added $(500 \mu \mathrm{l})$ to the solution of fibers in 1,4dioxane $(1 / 1 \mathrm{v} / \mathrm{v})$ in the screw-capped test tubes, then heated at $100{ }^{\circ} \mathrm{C}$ for 15 minutes and finally cooled in an ice bath. At the end, $3 \mathrm{ml}$ of 1,4-dioxane was added into each tube, thoroughly mixed with a Vortex mixer and absorbance at $570 \mathrm{~nm}$ was measured with UVIKON $810 \mathrm{UV}$-vis spectrophotometer. The calibration curve of PCL-N $\mathrm{N}_{3}$ polymer powder was obtained following the same procedure as described for f-PCL-N 3 fibers (see Figure S1, Supplementary Material).

Viscosity measurements were done using MCR301 and MARS III controlled-stress rheometers equipped with cone-plate geometry: $60 \mathrm{~mm}$ titan cone, having $1^{\circ}$ angle and $29 \mu \mathrm{m}$ and $53 \mu \mathrm{m}$ gap, respectively.

Field Emission - Scanning Electron Microscope (FESEM ZEISS ULTRA55) was used for observing the morphology of the fibers at $1 \mathrm{kV}$ accelerating voltage, $5 \mathrm{~mm}$ of working distance and at magnifications of 500, 1000 and 2000 times using In-Lens detection system. All samples were sputter coated with Pt of $1 \mathrm{~nm}$ thickness. Average fiber diameters of the electrospun fibers, were obtained as a mean value of 150 different diameters measured by Image J software. 
Fluorescence intensity of the fibers was monitored using Leica TCS SP2 AOBS (Acoustico Optical Beam Splitter) confocal laser scanning system and an inverted fluorescence microscope equipped with an oil-immersion objective lens $40 \times$. Fibrous samples were put in between two lamellae and covered with $4 \mu \mathrm{l}$ of stock solution (acetonitrile/water). FITC-labeled fibers were visualized by excitation of the fluorophore with a $488 \mathrm{~nm} \mathrm{Ar}-\mathrm{Kr}$ laser and the emitted fluorescence was collected between 508 and $533 \mathrm{~nm}$, precisely defined by the AOBS.

\section{Results and Discussion}

Chemical transformations of the hydroxyl groups into tosyle and azido moieties were proved by ${ }^{1} \mathrm{H}$ NMR as represented in the Figure 1. Efficiency of the tosylation reaction was evidenced by the presence of characteristic signals of both the aromatic and methyl group at 7.77-7.31 ppm and $2.42 \mathrm{ppm}$, respectively. Final substitution of the tosyl group into the azide functions was represented with the characteristic triplet at 3.26-3.23 ppm. Additional analyses by FT-IR and MALDI-TOF mass spectrometry unambiguously confirmed the structure of the PCL-N 3 polymer (see Supporting Information).

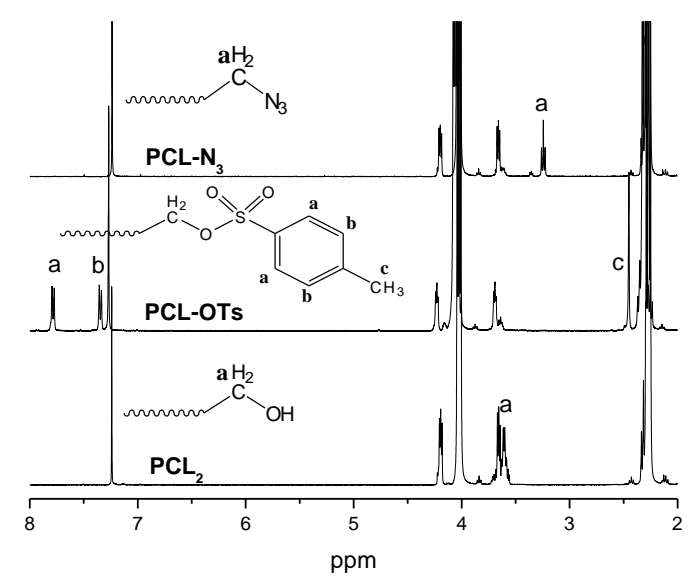


Figure 1. ${ }^{1} \mathrm{H}$ NMR $(400 \mathrm{~Hz})$ superposed spectra of the $\mathrm{PCL}_{2}$, PCL-OTs and PCL-N 3 polymers in $\mathrm{CDCl}_{3}$

During the electrospinning process, in order to obtain a continuous polymer jet, it is important to know at which concentration chain entanglements occur. ${ }^{27}$ For that purpose, zero-shear viscosity in function of $\mathrm{PCL}_{80}$ concentration in dichloromethane/methanol (4:1) solvent mixture was traced using controlled-stress rheometer and a critical $\left(\mathrm{c}^{*}\right)$ concentration was determined (Fig S7, ESI). Assuring high-molecular-weight chain entanglements, polymer solutions of both homopolymer PCL 80 and polymer blends PCL $_{80} /$ PCL-N $_{3}$ were prepared in such a way that individual $\mathrm{PCL}_{80}$ concentration was always kept above its $\mathrm{c}^{*}$ concentration (see Table 1). ${ }^{28,29}$

Table 1. Electrospinning parameters for non-derivative $\mathrm{PCL}_{80}$ and azide-functionalized fibers: fPCL-N $3-20,-40$ and -60 and their mean diameter

\begin{tabular}{|c|c|c|c|c|c|c|c|}
\hline $\begin{array}{l}\text { Electrospun } \\
\text { fibers }\end{array}$ & $\begin{array}{c}\text { Total Polymer } \\
\text { wt } \%\end{array}$ & $\begin{array}{l}\mathrm{PCL}_{80} \\
\text { wt } \%\end{array}$ & $\begin{array}{c}\text { PCL-N } 3 \\
\text { wt } \%\end{array}$ & $\begin{array}{c}\text { Flow rate } \\
\mathrm{ml} / \mathrm{min}\end{array}$ & $\begin{array}{c}\text { Voltage } \\
\mathrm{kV}\end{array}$ & $\begin{array}{c}\mathrm{RH}^{\mathrm{a}} \\
\%\end{array}$ & $\begin{array}{c}\text { Fiber } \\
\text { diameter }^{b} \\
n m\end{array}$ \\
\hline $\mathrm{PCL}_{80}$ & 8 & 8 & 0 & 0,01 & 13 & 55 & $591 \pm 283$ \\
\hline f-PCL-N ${ }_{3}-20$ & 10 & 8 & 2 & 0,015 & 14 & 49 & $567 \pm 301$ \\
\hline f-PCL-N $3-40$ & 16 & 9,6 & 6,4 & 0,015 & 14 & 30 & $547 \pm 68$ \\
\hline f-PCL-N $3-60$ & 23 & 9,2 & 13,8 & 0,02 & 13 & 36 & $694 \pm 149$ \\
\hline
\end{tabular}

${ }^{a}$ Relative humidity

${ }^{\mathrm{b}}$ Average fiber diameter \pm standard deviation

The synthesized PCL-N 3 polymer was blended with $\mathrm{PCL}_{80}$ at different ratios, and electrospun fibers were marked as f-PCL-N $3-20$, f-PCL-N $3-40$, f-PCL-N $3-60$, corresponding to 20 wt $\%, 40$ $\mathrm{wt} \%$ and $60 \mathrm{wt} \%$ of PCL-N $\mathrm{N}_{3}$ respectively, where $60 \mathrm{wt} \%$ of functionalized PCL-N $\mathrm{N}_{3}$ was the 
upper limit for obtaining the uniform beadless fibers with submicron diameters. All fibrous scaffolds were observed using FESEM microscopy and their average fiber diameter was obtained as a mean value of 150 measurements. FESEM images (Figure 2 A-D) show that the presence of azide-functionalized $\mathrm{PCL}_{2}$ does not modify significantly the size and morphology of the fibers. The statistical analysis of all fiber diameters measured show rather constant value of about 600 $\mathrm{nm}$ (Table 1) and a slender fiber-diameter distribution under dry air atmosphere. It is interesting to notice that keeping the $\mathrm{PCL}_{80}$ concentration nearly constant while increasing the concentration of PCL-N $\mathrm{N}_{3}$ didn't influence the fiber diameter. The effect of azide groups and the presence of low molecular weight PCL chains on polymer blends have been evaluated through rheological investigations (see Figure S8, SI). In the presence of low molecular weight PCL, the viscosity curve of blends is slightly shifted towards higher values, due to increase in concentration, but not sufficiently to increase the fiber diameter. Consequently, the fiber diameter appears to be directed by high-molecular-weight polymer chains. Moreover, viscosity curves of functionalized PCL $80 / \mathrm{PCL} \mathrm{N}_{3}$ and non-functionalized $\mathrm{PCL}_{80} / \mathrm{PCL}_{2}$ blends are nearly superimposed, showing that no significant associative interactions between azide groups and PCL chains occur in this blend. Indeed, the density of azide groups is low and the solvent mixture is mostly nonpolar, restricting intra and intermolecular associations through hydrogen bonding. These results could explain the constant diameter of the electrospun fibers observed by FESEM. 

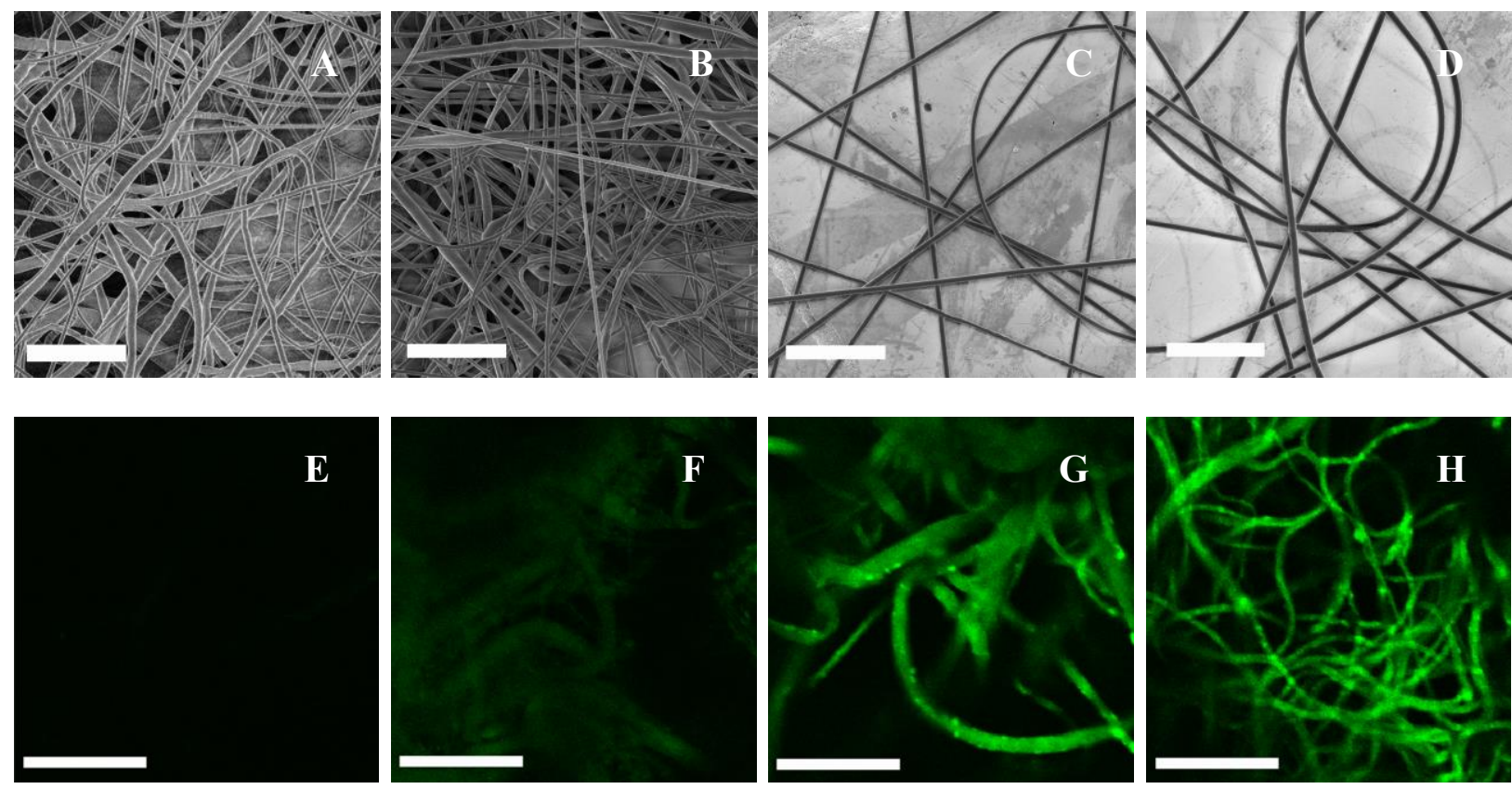

Figure 2. FESEM images (A-D) and fluorescent images (E-H) of f-PCL $\mathrm{L}_{80}$ fibers containing: 0 wt\% (A,E), $20 \mathrm{wt} \%(\mathrm{~B}, \mathrm{~F}), 40 \mathrm{wt} \%(\mathrm{C}, \mathrm{G})$ and $60 \mathrm{wt} \%(\mathrm{D}, \mathrm{H})$ of PCL-N $\mathrm{N}_{3}$. For fluorescence microscopy, prior observation, all samples were incubated with FITC-alkyne fluorophore and copper catalysts. Scale bar $10 \mu \mathrm{m}(\mathrm{A}-\mathrm{D})$ and $20 \mu \mathrm{m}(\mathrm{E}-\mathrm{H})$.

Quantification of azide groups available at the surface of electrospun f-PCL-N $\mathrm{N}_{3}$ fibrous scaffolds was further assessed by a colorimetric assay. Surface azides were reduced with triphenylphosphine $\left(\mathrm{PPh}_{3}\right)$ in a solid-liquid phase (fibers-ethanol), the resulting amino-fibers were dissolved in 1,4-dioxane and finally quantified by the Keiser-ninhydrin method. ${ }^{30-32}$ Without the $\mathrm{PPh}_{3}$ reducing agent, these fibers showed no specific coloration under ninhydrin assay, proving that the azide groups were intact during the electrospinning process.

The results of the ninhydrin assay are shown on Figure 3. Weight percentage of PCL-N $\mathrm{N}_{3}$ on the surface represents experimentally-found mass of PCL-N $\mathrm{N}_{3}$ per total mass of the tested sample, and it is expressed as experimental value (in grey) while initial concentration of PCL- $\mathrm{N}_{3}$ in the electrospinning solution is represented in white. Total amount of azides (Figure 3, white 
columns) is the amount of PCL-N 3 initially present in the solution (Table 1). The difference between gray and white column stands for a non-accessible PCL-N $\mathrm{N}_{3}$ mass per cent inside the fibers or the film. Concentrations of the PCL-N $\mathrm{N}_{3}$ on the surface were calculated from the PCL-N calibration curve (see SI, Figure S1). Figure 3 clearly points out that, for the electrospun fibers, about $80 \%$ of functionalized azide groups are located on the fiber's surface.

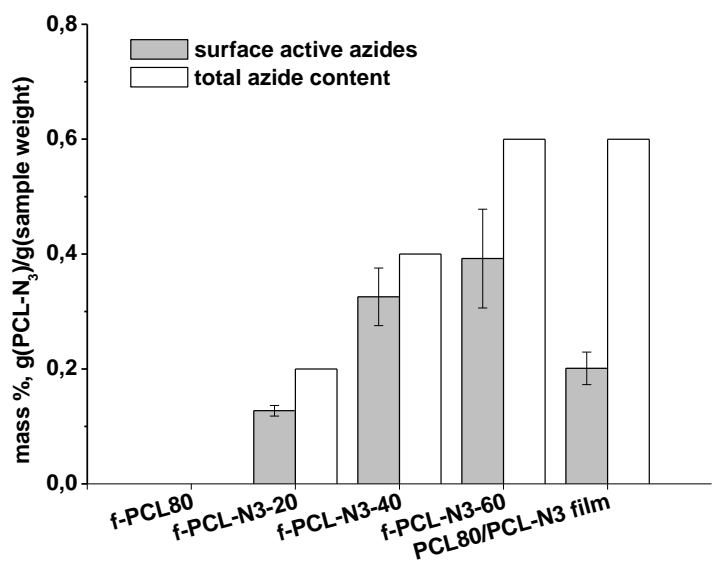

Figure 3. Quantification of azides groups on the surface of the f-PCL $\mathrm{L}_{80}$, f-PCL-N $\mathrm{N}_{3}-20$, f-PCL-N $\mathrm{N}_{3}$ 40, f-PCL-N $\mathrm{N}_{3}-60$ fibers and PCL $\mathrm{P}_{80} / \mathrm{PCL}-\mathrm{N}_{3}$ cast film that contain $0,20,40,60$ and 60 mass $\%$ of the functionalized PCL- $\mathrm{N}_{3}$, respectively

Colorimetric results, defining azide concentration on the surface of the fibers, suggest a surface aggregation of the azides groups. Might this be due to a spontaneous aggregation of azide groups to the solution/air interface or simply induced by the electric field? As observed by S. J. Hardman and coworkers, ${ }^{33}$ addition of even small quantities of fluorocarbon (CF) functionalized polymer additives to polystyrene solution results in their surface segregation during electrospinning. However, they remind that the segregation of CF groups occurs even without 
the action of the electric field. ${ }^{34}$ In addition, Stachewitz and Barber ${ }^{35,36}$ indicated on the chemical group orientation at the surface of electrospun fibers due to polar contribution of polyamide chains. Also, they observed a similar behavior in a cast film after mechanical drawing above the glass-transition temperature. As clearly demonstrated by Fu et al. ${ }^{3637}$ for PS bearing polar alkylbromide group (C-Br), such segregation can be significantly enhanced by the polarization of chemical groups induced by the electric field. Indeed, positive charges of polymer jet drive alkyl bromide groups to the surface by electrostatic interactions, while for the nanofibers electrospun with an anode positioned at spinneret, unpolarized $\mathrm{C}-\mathrm{Br}$ groups remain in the bulk. X.-Y. Sun et $a l .{ }^{38}$ showed that the electric field used in electrospinning could promote surface segregation of not only small chemical groups but also large peptide segments. It is known that azide groups can be polarized and bear partially negative charges $(\delta-) .{ }^{39}$ In our case, PCL80/PCL-N ${ }_{3}$ fibers have been obtained by using a cathode on the spinneret (Figure 4). Consequently, it is reasonable to consider that azide group migration at fiber surface could be induced principally by electric field even if the spontaneous migration of azide groups towards the air/liquid interface cannot be excluded. Quantification of azide groups was performed on a cast polymer film from the $\mathrm{PCL}_{80} / \mathrm{PCL}-\mathrm{N}_{3}$ blend (mass ratio $2 / 3$ ) in $\mathrm{DCM} / \mathrm{MeOH}$ (volume ratio $4: 1$ ) solvent mixture to investigate the possible spontaneous migration of azides at the polymer/air interface. With slow evaporation kinetics of few minutes for the cast film, the polymer chains as well as chemical groups have the ability to find spontaneously a preferable conformation. However, the colorimetric measurements performed on the cast film showed only $20 \%$ of the azides on the surface. This result has to be compared with the extremely fast evaporation kinetics of about few milliseconds for the electrospun fibers where about $80 \%$ of azide groups were located on the fiber surface. The evaporation process of volatile solvents is extremely fast during 
electrospinning and this spontaneous migration, hindered by the sharp increase of the solution viscosity, is only partial. Consequently, surface segregation of azide groups is likely due to electrically induced polarization rather than spontaneous interface attraction. This interpretation has been confirmed by the colorimetric quantification experiments, where azide concentrations on the surface of the polymer cast film decreased for more than double than the one of electrospun fibers (Figure 3). Additionally, increase of PCL-N $\mathrm{N}_{3}$ concentration in the electrospinning solution increased the concentration of azides on the surface of the fibers.

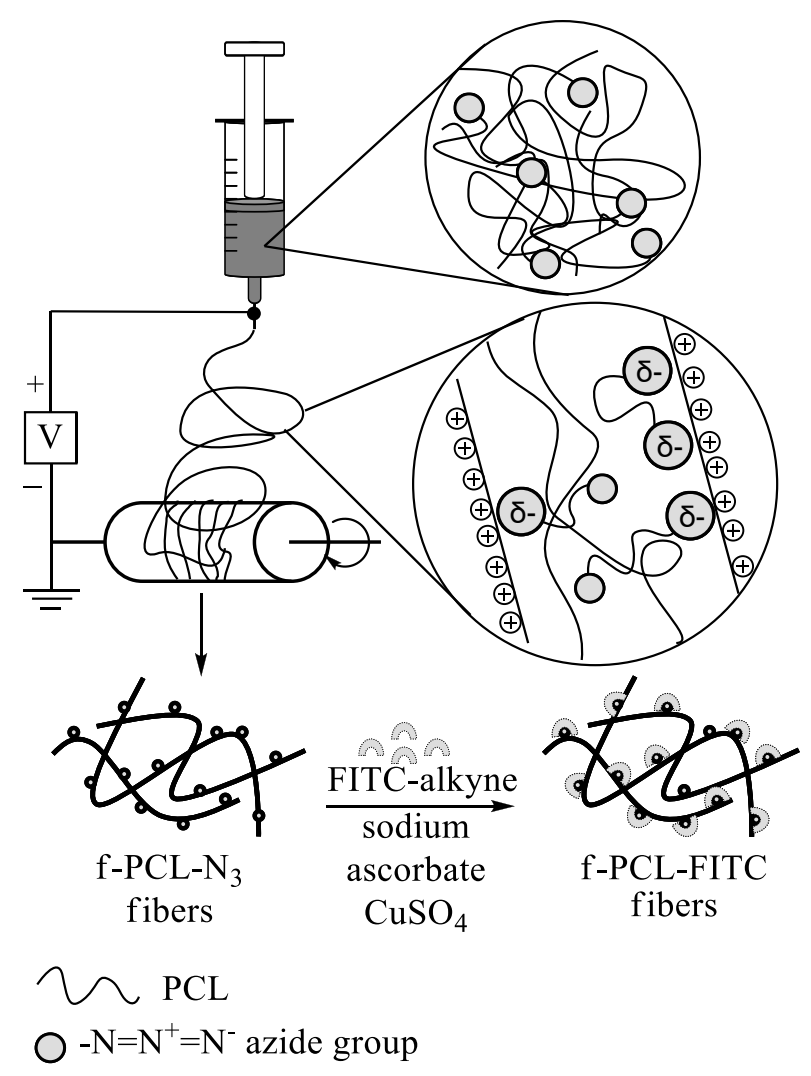

Figure 4. Schematic representation of the electrospinning setup with illustrated electrostatic attractions between negatively polarized azides $(\delta$-) and positively charged surface during the electrospinning, as well as click reaction of f-PCL-N ${ }_{3}$ fibers with FITC-alkyne with the resulting f-PCL-FITC fluorescent fibers 
Fluorescent labeling of f-PCL-N 3 fibers with FITC-alkyne fluorophore using click chemistry enabled us to investigate the accessibility and reactivity of the surface azides (Figure 2 E-H). fPCL80, f-PCL-N $3-20,-40$ and -60 fibrous scaffolds were incubated with the FITC-alkyne dissolved in acetonitrile-water (1:1) solvent mixture, with and without copper(I)/sodium ascorbate catalysts. Without the catalysts, all tested samples exhibited no fiber coloration, demonstrating that there is no non-specific adsorption of the FITC fluorophore on the PCL (see SI, Figure S9). By adding the catalysts, f-PCL 80 remained non-colored while azide-containing fibers f-PCL-N $\mathrm{N}_{3}-20,-40$ and -60 showed strong fluorescence at $520 \mathrm{~nm}$ and uniform coloration on the surface (Figure $2 \mathrm{E}-\mathrm{H}$ ) testifying the accessibility and reactivity of the surface azides. A gradual increase of color intensity, clearly visible to the naked eye, from f-PCL-N ${ }_{3}-20$ to f-PCL$\mathrm{N}_{3}-60$ corresponds to a degree of FITC fluorophore implemented onto the fibers (Figure 5). This macroscopical observation correlates accurately with the results obtained using confocal microscopy. The fluorescent labeling confirmed that surface-azides could be easily accessed and coupled by heterogeneous click chemistry.

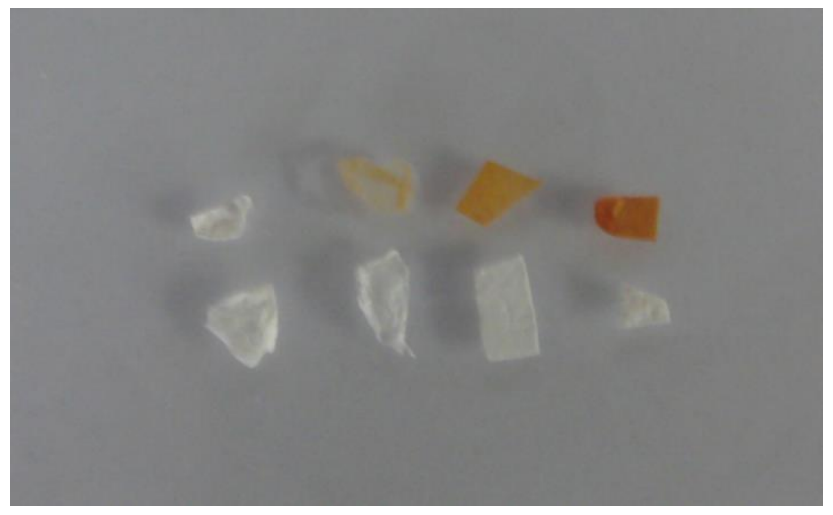

Figure 5. The image (from left to right) of $\mathrm{PCL}_{80}$, f-PCL-N ${ }_{3}-20$, f-PCL-N ${ }_{3}-40$ and f-PCL-N ${ }_{3}-60$ fibers after incubation with FITC-alkyne, with (top line) and without catalysts (bottom line), demonstrates successful attachment of the FITC fluorophore by click chemistry and macroscopically visible differences in the grafting ratio 
Our results show that by electrospinning commercially available unfunctionalized PCL and PCL-N $\mathrm{N}_{3}$ polymers, it is possible to obtain highly surface decorated clickable nanofibers. We demonstrated that azides suffer no change during the electrospinning and could be easily accessed for click conjugation.

Additionally, it is interesting to notice that a chemical reduction of azides to amines using $\mathrm{PPh}_{3}$ could serve as a simple route for obtaining highly amine-functionalized PCL fibers. Aminofibers of biocompatible PCL could further react by means of peptide coupling with versatile proteins, thus serve as an important precursor to advanced biomaterials for biological and cell culture applications.

\section{Conclusion}

In this paper we reported a non-invasive approach of fiber's surface functionalization. Azidefunctionalized PCL of low molecular weight was efficiently electrospun together with a nonderivative PCL of high molecular weight to provide clickable fibers. Unlike saponification or aminolysis, which are commonly used method for functionalization of PCL fibers, the methodology reported here is high-yielding and non-destructive. Colorimetric results showed that, due to the electrostatic attraction forces during the electrospinning process, about $80 \%$ of all implemented azides are present on the fiber's surface. Reduction of azides to amines by using $\mathrm{PPh}_{3}$ revealed a potential of these fibers to offer highly amine-functionalized surfaces as well. Furthermore, incorporation of the FITC fluorophore highlighted the availability of azide groups for click chemistry reaction. We could summarize that, either in form of azides or amines, these scaffolds can be involved in versatile reactions, click chemistry or peptide coupling, tailoring the bio-active and reinforced surfaces. 
Supporting Information. Additional information about ninhydrin test calibration curve, NMR, FTIR and MALDI-TOF mass spectroscopy of end-functionalized PCL as well as shear viscosity measurements and fluorescence imaging. This material is available free of charge via the Internet at http://pubs.acs.org

\section{Corresponding Author}

Frédéric Bossard*

Laboratoire Rhéologie et Procédés, UMR 5520, Université Joseph-Fourier - Grenoble Institut National Polytechnique

1301 rue de la piscine, 38041 Grenoble, Cedex 9, France

E-mail: frederic.bossard@ujf-grenoble.fr

\section{Author Contributions}

All authors have given approval to the final version of the manuscript.

\section{Funding Sources}

This research was supported by the grant of Institut Carnot "Polynat" and the MNERT PhD grant $N^{\circ} 2010 / A 8$ to A. Lancuški.

\section{ACKNOWLEDGMENT}

The authors gratefully acknowledge S. Pradeau for practical assistance in preparation of PCLN3, R. Martin for her expert help and technical assistance in FESEM microscopy, S. Boullanger and A. Durrand-Terrasson for their technical assistance in mass spectrometry analyses and fluorescence microscopy, respectively. We also thank the Institut Carnot "Polynat" for financial support and the MNERT for PhD grant N²010/A8 to A. Lancuški. 


\section{ABBREVIATIONS}

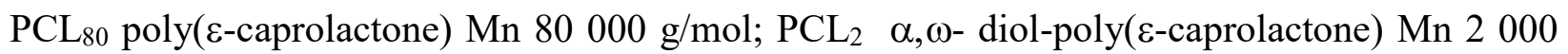
g/mol; PCL-OTs $\alpha, \omega$-p-toluenesulfonyl-poly( $\varepsilon$-caprolactone); $\quad$ PCL-N $3 \quad \alpha, \omega$-azido-poly( $\varepsilon$ caprolactone); FITC fluorescein isothiocyanate; f-PCL-FITC fluorescein isothiocyanatemodified PCL fibers; f-PCL 80 poly( $\varepsilon$-caprolactone) fibers; f-PCL-N 3 -20 fibers containing 20 $\mathrm{wt} \%$ of PCL- $\mathrm{N}_{3}$ and $80 \mathrm{wt} \%$ of non-derivative poly( $\varepsilon$-caprolactone); f-PCL-N $3-40$ fibers containing $40 \mathrm{wt} \%$ of PCL-N 3 and $60 \mathrm{wt} \%$ of non-derivative poly( $\varepsilon$-caprolactone); f-PCL-N $3-60$ fibers containing $60 \mathrm{wt} \%$ of PCL-N 3 and $40 \mathrm{wt} \%$ of non-derivative poly( $\varepsilon$-caprolactone); FT-IR furier-transform infra-red spectroscopy; NMR nuclear magnetic resonance; MALDI TOF MS matrix-assisted laser desorption/ionization time-of-flight mass spectroscopy; FESEM field emission scanning electron microscopy. CuAAc copper catalyzed azide alkyne cycloaddition.

\section{REFERENCES}

(1) Stevens, M. M.; George, J. H. Science, 2005, 310, 1135-1138.

(2) Agarwal, S.; Wendorff, J. H.; Greiner, A. Macromol. Rapid Commun., 2010, 31, 13171331.

(3) Nair, L. S.; Laurencin, C. T.; Prog. Polym. Sci., 2007, 32, 762-798.

(4) X. Liu, P. K. Chu, C. Ding, Mater. Sci. Eng., R, 2010, 70, 275-302.

(5) Agarwal, S.; Wendorff, J. H.; Greiner, A.; Adv. Mater., 2009, 21, 3343-3351.

(6) Croll, T. I.; O’Connor, A. J.; Stevens, G. W.; Cooper-White, J. J. Biomacromolecules, 2004, 5, 463-473. 
(7) Wulf, K.; Teske, M.; Löbler, M.; Luderer, F.; Schmitz, K.; Sternberg, K. J. Biomed. Mater. Res., Part B, 2011, 98B, 89-100.

(8) Huisgen, R. Angew. Chem. Int. Ed. Engl., 1963, 2, 633-645.

(9) Huisgen, R. Angew. Chem. Int. Ed. Engl., 1963, 2, 565-598.

(10) Kolb, H. C., Finn, M. G.; Sharpless, K. B. Angew. Chem. Int. Ed., 2001, 40, 2004-2021.

(11) Whittaker, M. R.; Urbani, C. N.; Monteiro, M. J. J. Am. Chem. Soc., 2006, 128, 1136011361.

(12) Wang, Q.; Chan, T. R.; Hilgraf, R.; Fokin, V. V.; Sharpless, K. B.; Finn, M. G. J. Am. Chem. Soc., 2003, 125, 3192-3193.

(13) Fleischmann, S.; Hinrichs, K.; Oertel, U.; Reichelt, S.; Eichhorn, K.-J.; Voit, B. Macromol. Rapid Commun., 2008, 29, 1177-1185.

(14) Fu, G. D.; Xu, L. Q.; Yao, F.; Zhang, K.; Wang, X. F.; Zhu, M. F.; Nie, S. Z. ACS Appl. Mater. Interfaces, 2009, 1, 239-243.

(15) Chang, Z.; Xu, Y.; Zhao, X.; Zhang, Q.; Chen, D. ACS Appl. Mater. Interfaces, 2009, 1, 2804-2811.

(16) Shi, Q.; Chen, X.; Lu, T.; Jing, X. Biomaterials, 2008, 29, 1118-1126.

(17) Yao, F.; Xu, L.; Lin, B.; Fu, G.-D. Nanoscale, 2010, 2, 1348-1357.

(18) Teo, W. E.; Ramakrishna, S. Nanotechnology, 2006, 17, R89-R106.

(19) Doshi, J.; Reneker, D. H. J. Electrostatics, 1995, 35, 151-160. 
(20) Yarin, A. L.; Koombhongse, S.; Reneker, D. H. J. Appl. Phys., 2001, 90, 4836-4846.

(21) Woodruff, M. A.; Hutmacher, D. W. Prog. Polym. Sci., 2010, 35, 1217-1256.

(22) Mattanavee, W.; Suwantong, O.; Puthong, S.; Bunaprasert, T.; Hoven, V. P.; Supaphol, P. ACS Appl. Mater. Interfaces, 2009, 1, 1076-1085.

(23) Ghasemi-Mobarakeh, L.; Prabhakaran, M. P.; Morshed, M.; Nasr-Esfahani, M. H.; Ramakrishna, S. Mater. Sci. Eng., C, 2010, 30, 1129-1136.

(24) Zander, N. E.; Orlicki, J. A.; Rawlett, A. M.; Beebe, T. P. ACS Appl. Mater. Interfaces, 2012, 4, 2074-2081.

(25) Krouit, M.; Bras, J.; Belgacem, M. N. Eur. Polym. J., 2008, 44, 4074-4081.

(26) Xu, C.; Ye, L. Chem. Commun., 2011, 47, 6096-6098.

(27) Ramakrishna, S.; Fujihara, K.; Teo, W. E.; Lim, T. C.; Ma, Z. An Introduction to Electrospinning and Nanofibers, World Scientific Publishing Co Pte Ltd, 2005, p 91-102.

(28) Gupta, P.; Elkins, C.; Long, T. E.; Wilkes, G. L. Polymer, 2005, 46, 4799-4810.

(29) McKee, M. G.; Wilkes, G. L.; Colby, R. H.; Long, T. E. Polymer, 2004, 37, 1760-1767.

(30) Sun, S.-W.; Lin, Y.-C.; Weng, Y.-M.; Chen, M.-J. J. Food Compos. Anal., 2006, 19, 112117.

(31) Punna, S.; Finn, M. G. Synlett, 2004, 1, 99-100.

(32) Lamothe, P. J.; McCormick, P. G. Anal. Chem., 1973, 45, 1906-1911. 
(33) Hardman, S. J.; Muhamed-Sarih, N.; Riggs, H. J.; Thompson, R. L.; Rigby, J.; Bergius, W. N. A.; Hutchings, L. R. Macromol. 2011, 44, 6461-6470.

(34) Ansari, I. A.; Clarke, N.; Hutchings, L. R.; Pillay-Narrainen, A.; Terry, A. E.; Thompson, R. L.; Webster, J. R. P. Langmuir 2007, 23, 4405-4413.

(35) Stachewicz, U.; Barber, A. H. Langmuir, 2011, 27, 3024-3029.

(36) Stachewicz, U.; Li, S.; Bilotti, E.; Barber, A. H. Appl. Phys. Lett., 2012, 100, 094104-2.

(37) Fu, G. D.; Lei, J. Y.; Yao, C.; Li, X. S.; Yao, F.; Nie, S. Z.; Kang, E. T.; Neoh, K. G. Macromolecules, 2008, 41, 6854-6858.

(38) Sun, X.-Y.; Shankar, R.; Borner, H. G., Ghosh, T. K.; Spontak, R. J. Adv. Mater., 2007, 19, 87-91.

(39) Chen, F.-F.; Wang, F. Molecules, 2009, 14, 2656-2668.

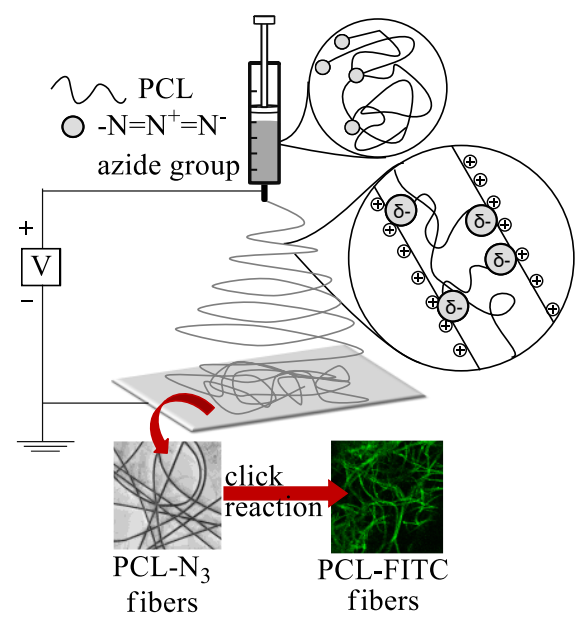

